\title{
Beyond the Barriers: Witnessing Shifting Gender Dynamics in Multinational Ghanaian Mine Jobs
}

\author{
Rufai Haruna Kilu \\ Lulea University of Technology, Division of Human Work Science, Department of Business Administration- \\ Sweden \\ Box 971 87- Lulea \\ +46734858950 \\ rufai.haruna.kilu@Itu.se / hkrufai@gmail.com
}

\begin{abstract}
Gender and technology are central to socioeconomic development and corporate innovation. However, the multinational Ghanaian mining is dominated by men and masculinity cultures. The current paper therefore understudy the Ghanaian mines, expose their homogeneous scope, and examine the sociocultural barriers constraining effective mine work participation of women. The paper also explores the transformations that have occurred, occasioning a shift in gender dynamics, leading to an increasing number of women participation in the mines. Deploying a multiple case study, qualitative research design, and meta-narratives of the respondents. The results point to the common prejudices, perceptions and implicit stereotyped notions of gender roles in the mines as noted sociocultural factors constraining effective participation of women in mine work. However beyond barriers, the paper intuits a phenomenon of a "women revolution" in the mines, witnessing collective efforts from mining companies and allied institutions adopting gender strategic measures, such as the "ore solidarity" gender mainstreaming in admission programs as well as "gender-driven mining" initiatives aimed at re-engineering a shift in gender dynamics in the mine jobs of Ghana. These change regimes among the mines implies inclusivity, defeminization of poverty, towards achieving organizational modernization, competitiveness and an assurance for gender driven social innovative mining.
\end{abstract}

Keywords: Sociocultural, barriers, male-dominance, Shifting gender dynamics, Ghanaian mines 


\section{Introduction}

This study explores the multinational Ghanaian mines, questions their long standing maledominance and masculinity cultures with consequential effects of women facing the realities of participatory barriers. This phenomenon is critically problematized by the current paper. For a scientific comprehension of this circumstance, however, it is prudent to delve into the gendered organizational nature of mine work. This work, therefore, aims at reflecting consciously upon the sociocultural barriers affecting effective participation of Ghanaian women in mine jobs. Beyond the barriers, nonetheless, the study unmasks current changes that have occurred, stimulating a shift in background dispositions and gender dynamics, leading to the participation of an increasing number of women in the industry. The paper by structurally discusses the study context for a full grasp and comprehension of relevant issues pertaining to organizational gender perspectives. The method and material used is equally explained to provide an account of the process under which data was collected. A summary of the theoretical framework used to provide the scientific basis, explanations and discussions of the results.

Ghana is a major player in the gold mining industry; globally ranked among the top ten, and placed second to South Africa in the Sub-Saharan Africa (AGS, 2010). Gold is currently mined in commercial quantities across six out of Ghana's ten administrative regions. Other minerals being mined include diamond, manganese, iron, bauxite, natural gas, petroleum, salt, cement, and silver. The gold mining industry in Ghana is characterized by a hybrid of practices, policies, and procedures; with economic and socio-structural ramifications, in areas of job creation, GDP growth, royalties, and revenue mobilizations to the state (Kilu, Andersson, Sanda \& Uden, 2016). But still, the mining industry is characterized with gender inequalities, constituting participatory barriers that this paper put under lens. And through this gender inequality lens, we view the multinational Ghanaian mines emerge gendered spaces, while mining authorities emerged visibly gendered actors in violation of conventional history of industrial world of mine work. The current paper therefore seeks to identify the sociocultural barriers affecting effective mine work participation of women, and beyond the barriers; to explore the transformations that have occurred, occasioning a change in gender dynamics, leading to increasing number of women participation in Ghanaian mines.

The mining industry globally is a classic male-dominated sector (Benya 2009; Lahiri-Dutt \& Macintyre 2006; Andersson, Faltholm, Abrahamsson \& Lindberg, 2013). A profile of gender representation proportions to create a sense of sex composition among employees from four understudied mining companies was done in Ghana (Kilu, et al, 2016) featuring statistical data sourced from various Human Resource Managers aim at explaining employees' status by gender in those companies. The statistical figures showed that majority of employees in multinational Ghanaian mines are men. Suggesting an average between $85-95 \%$ of the workforce being men across management, supervisory, core operations and ancillary work positions.

Similarly, among the mine business partners, nearly all workers are men (Kilu, et al, 2016). The paper speaks here of contractors, consultants, transportation companies, manufacturers and suppliers engaged to provide civil engineering works, the supply of hard and soft mining packages, 
drilling, blasting, crushing and grinding. Another critical agent in the mine work political structure is the Ghana Mineworkers' Union of Trade Union Congress. Membership of the unions across the mines, both senior and junior member categories, weigh heavily towards the men. Also, the leadership is male. The concerns being raised in the current work against male-dominance cultures supports research in Swedish mining industry by Abrahamsson (2008) and Andersson et al (2013) where concerns are expressed that though the mining industry may have evolved in many respects, old beliefs on the close relationship between mining and masculinity still exist: an idealization of a certain type of miner masculinity deep rooted in the old manual, heavy and dangerous mining work, characterized by macho masculinities. Olofsson (2010) added some male mine workers may view new technological inventions such as automation, computerization, and robotization as a feminization of their perceived male work, breeding an attitude that may manifest as a direct resistance to women and gender equality. Then Ahmad and Lahiri-Dutt (2006) in Asia Pacific described how large scale mining projects are being characterized with physical demands, capital intensive, production driven, and mostly associated with masculinity. Her concerns do not only bother on overt visibility of men but a taken for granted conflation of men, with institutionalized authority expertise and prestige, institutions, laws, and structures of governance that do not favor gender neutrality. Hence the mine job is often viewed a macho space, where masculinity takes a center stage.

In the continent of Africa, Benya (2009) studied the platinum mines near Rustenburg in South Africa to explore the masculine occupational culture in underground work in the mines. The work showed that women were perceived as lazy individuals who slowed down the work processes. In a similar vein, Amutabi and Lutta-Mukhebi (2001) in Kenya examined the role of women in mining compared to that of men. The results showed that women in mining had not been thoroughly researched and documented, and that women's mine work contribution is often not acknowledged. These South African and Kenyan cases are yet other wild perceptual and stereotype notions against women. Arguably, this universal male-dominance has become phenomenal in the mining sector, presenting a situation which in the view of the author requires a holistic approach, hence the need for this current study.

Relative to the observed global problematic male-dominance in mine works, Ghana's storyline is generating research interest on grounds of literature and knowledge gaps. Certainly, extant literature and empirical studies do exist on mining, technology and organizational gender perspectives; more especially on women in mining. But the geographical context of such works are mostly limited to Europe, Asia, United States and Australia, among others. Studies on Africa are woefully scarce, and Ghanaian ones very few. This work attempts to set the stage for the contemporary study into the area.

This could be contemplated as a 'doing gender' of a sort, practices where virtually every activity is being socially assessed as to its manly or womanly nature (West \& Zimmerman 1989). Doing gender is structural and cultural. It bothers on binary oppositions and hierarchical privileges. The binary oppositions are; male-female, masculine-feminine, boy-girl and man-woman. And the hierarchical privileges juxtaposes how the former dominate and occupy a commanding position over the later (Levi-Straus, 1973). Doing gender means creating differences between girls and boys or men and women. Differences that are not natural, essential or biological, but sociocultural driven differences; and this theory is popular in creating understanding as to how societal and 
organizational gendered natures have been socially constructed and sustained. For West and Zimmerman (1987) gender analysis is a distinctively sociological understanding of routines, methodical and recurring accomplishments under taken by both men and women, whose competences as members of society is hostage to its production and reproduction. In this sense, it might be fair to acknowledge that modern work organizations like the mines are microcosms of modern societies, and so far as almost every activity in society is partitioned on the basis of gender, doing gender might be unavoidable in the mining industry as well.

\section{Theoretical Framework}

There are growing attention to 'doing-gender' and 'undoing-gender' through and within the respective broad structuralist (Levi-Straus, 1973) and poststructuralist (Derrida) approaches. And within these broad theoretical areas, this work specifically applied the 'doing gender' (West and Zimmerman 1987) 'undoing gender' (Butler 2004; Deutsch 2007) and 'the new social movement' (Melucci, 1997).

Doing gender is an applied theory in work and organizational studies, which demonstrate how gender is constructed through interactions in organizations. Recent studies have also started looking at how gender can be undone. The doing gender approach mostly is drawn upon by organizational researchers to explain the fluidity, and changeable nature of gender, and something that is flourishing in organizational research (Linstead \& Pullen 2006; Poggio 2006). While doing gender is an approach regularly drawn upon by organizational researchers, the question of how gender can be undone is equally featuring in organizational researches. It is suggested that if one understands how gender is done at work, it might then be possible to undo it (Pullen, 2006). Doing gender approaches have been useful to show that gender is not a property of person but a process that people enact in everyday situations (Linstead \& Pullen 2006; Poggio, 2006). And once doing gender is understood and undone, the end product is a change; hence the new social movement theory with its change functionality being discussed alongside. This paper thereby examines gender, and how gender is done in terms of participatory barriers. The paper beyond the barriers, explores how gender is being undone to illicit change regimes among the multinational mine work organizations in Ghana.

West and Zimmerman (1987) further posits doing gender as an accomplishment, an achieved property of a situated conduct of a sort, and an emergent feature of a social situation, capable of triggering attentional shift from internal matters of the individual to focus on interactional and ultimately on institutional arenas. That in one sense, it is individuals who do gender, but a situated doing gender type, carried out in virtual or real presence of others who are presumed to be oriented towards its production and reproduction; a practical means of legitimizing the fundamental divisions of society. West and Zimmerman (1987) reiterated that doing gender involves a complex socially guided perceptions and stereotypes, as well as interactional and micro-political activities that cast and labels certain particular pursuits and roles as masculine and feminine. Acker posits much 'of the social and economic inequalities in the USA and other industrial countries originates from organizations, in their daily activities of working and organizing the work.' And this is what activists as well as feminist and civil rights reformers have based their actions on (2006, p. 441). Abrahamsson (2014) argued that gender equality could be seen as a prerequisite, or perhaps, even 
side effect of modern organizational concepts, and that work organizations may be more or less gendered in different ways, and that the gendering concept may affect individuals' possibilities, as well as organizational functionality in both short and long term.

Indeed, in synch with doing gender, gender division of labor has become real across Ghana, which manifests inter alia in women being given primary responsibilities like care giving, emotional management and maintenance of routine order, while in the public sphere men are given privileged access to what is described as the locus of true rewards of social life - money, status, power, freedom, opportunities for growth and self-worth (Apusiga, 1987). The Ghanaian society also exhibits several complementarities between men and women's roles. Men as a group enjoy more rights, power and privileges than women. Just as Ampofo (2014) argued that in many cases in Ghana, women's rights, power and enjoyment of privileges are tied to men as fathers, husbands and brothers. And certainly, women in Ghana suffer from greater inequalities than men. This is not by virtue of inherent deficiencies but because society is structured in ways that privilege men over women. It is therefore fair to argue that differences in gender and its implications for socioeconomic development exists in the Ghanaian society, and many institutional practices and processes, though may not overtly express discrimination against women, but they are not genderneutral, as the case may be in the Ghanaian mine jobs.

Yakovleva (2007) in Ghana, conducted a study to measure female participation in Ghanaian mine jobs. The results showed sociocultural taboos, domestic and family commitments impose heavy burden on women, hindering their independence and effectiveness to participate in mine work. Also, Alexander (2007) compared reasons why in the first three decades of the twentieth century, women worked underground in Indian mines but not in those of South Africa. Results suggest there was opposition to the employment of women in South African mines due to Africans dependence on women for both production and reproductive functions. Similarly, Amutabi and Lutta-Mukhebi (2001) in Kenya examined the role of women in mining, compared to that of men. The results showed that women in mining have not been thoroughly researched and documented, and that women mine work contribution is often blanketed together with that of men. Certainly, the knowledge of the fact that these mine work gendered practices and processes have wider range of variations, both from within and among cultures, and are as well subject to change, motivate counter arguments and propositions for deconstruction and undoing gender.

The current paper in its organizational gender and change orientations, is consistent with the undoing gender and the neoliberal social movement propositions. Butler (2004) believed the terms by which we are recognized as humans are socially articulated and are changeable. That the phrase "undoing gender" implies social interactions aim at reducing gender differences or behavior patterns in opposition to gender stereotypes. In other words, avoiding the use of stereotypes in evaluating others are actions directed at dismantling gender barriers. Similarly, in recognizing that language and words usage shape what our minds are drawn to, Deutsch (2007) posits we need a paradigm shift from talks on 'doing gender' to illuminating talks on how we can 'undo gender.' And in common parlance, 'undoing gender' evokes collective resistance instead of conformity to acts of 'doing gender.' Deutsch assumptions dovetails with those of other feminist theorists who articulate hopeful visions of change and the possibility of gender equality. For instance, Lorber (2000) notion of "degendering" and Risman's (1998) conception of "gender vertigo" both speak to the need to dismantling of gender, through putting in place policies, systems, structures and 
programs. Of course, it may take a lot more than changing terms to understand how to eliminate the structural gender systems. But at least paying attention to how we can undo gender, may keep us focused on how we can dismantle the gender system to create real equilibrium between men and women in work organizations.

The current paper also applied the neoliberal theory by Harvey (2005) which centered on collective actions for transformations towards achieving societal values. Thus, individual liberties, equality regimes, freedom and justice. Within the broad neoliberalism is the new social movement version, associated with theorists such as Touraine (2002) who focuses on the experiences, values, affiliations and actions of women involved in non-social movement organizations such as the multinational Ghanaian mines, and in my estimations, the present processes of change featuring the mining industry, come more clearly into view. The theory argued that attempts to understand social change hugely depends on key assumptions about the notion of change itself: firstly, that change should emanate from above; and, secondly, that change can best be understood when viewed at specific moments in time. That the theory looks beneath the surface of the observable to the invisible social linkages and subterranean networks of those with like mind who oppose the status quo. Certainly, the individuals, groups and organizations involved do not carry movement membership cards, but they do act collectively as well as separately. They unanimously share an orientation and values that oppose the status quo and those with power in order to render it visible and thereby negotiable. For Melucci (1995) involvement in social movement networks is sufficient in itself to provide purpose and meaningful identities for the participants who might, for example, choose to identify themselves with the women's movement or the environmental and ecological movement, or both of these. From this vantage point, the values and affiliations of movement supporters become significant, providing an impulse for the repositioning of those involved (Barry, Berg \& Chandler, 2007).

Advocates of this new social movement approach according to Barry, Berg and Chandler (2012) focused on examining the 'why' of a change, detailing the observable organizational characteristics, the submerged networks, affiliations and symbolic challenges to the dominant order. And of course the common purpose and ultimate goal of this theory, centered on the processes of action towards bring about a change, or some degree of reformism, suggesting that action and change take place along a continuum and attract a broad base of appeal as a result. The apparent characteristics of the new social movement theory are; first the members act collectively as well as separately, sharing values and orientations that are oppositional to the status quo. Secondly, the manner in which the members emerge is so spontaneous, suggesting the right time to step forth into brave new world of solidarity. And thirdly, the theory postulate social movement formations with members' collective values and orientations permeating into the fabric of social institutions, through a complex web of interactions Touraine (2002). This dominant new social movement, though originated from Europe in the 1960s, by 1980s, spread to the third world countries, making women's voices and experiences part of feminist knowledge production; and such movements spread across Africa by 1980s.

Ghana joined the new world order, witnessed formation of some feminine social movements of both local and international orientations. For instance, the $31^{\text {st }}$ December women's movement for example was formed in 1982. A local women's movement with branches across all the ten regions of Ghana. This movement, developmental oriented, founded with the goal of mobilizing women, 
both from rural and urban Ghana, aim at sensitizing women to understanding the governance of the country and wanted women to be part of the participatory democratic system, since women form majority of Ghana's population. The movement supported and promoted activities of women through education and capacity building. The movement also mentored women to enter mainstream political activities and many women are now Ministers, Party Functionaries, District Chief Executives, and Constituency Executives. The movement equally confronted family poverty issues, social exclusion, women's empowerment initiatives and championed promulgation of several laws to protect women and children's rights in Ghana. Example, they spear headed and got the Intestate Succession Law passed into PDNC Law 111 in 1985. The marriage and divorce registration Law, PNDC Law 112 which benefited all Ghanaian women. The movement also established day-care centers and nurseries, bakeries, fishing cooperatives, food-processing factories, and a host of socioeconomic programmes for women's empowerment. In light of this, the current paper argues that Ghana has long since, been familiar with, and adopted the 'new social movement theory' to fight issues of social inequalities, at the macro-political levels of the Ghanaian society. And now, we are witnessing a replica in adoption of this 'new social movement theory' at both mecro-organizational and micro-individual levels to champion the course, interest, values and orientations of women in mining Ghana.

\section{Methodology}

\section{Research design}

To investigate the two research questions, a qualitative approach was deployed on grounds that, it allows for results that reflect the perspectives of those being understudied (Czarniawska 2002), and also make room for that which cannot be quantified or where being quantified does not yield any meaningful insight (Gioia \& Chittipeddi 1991; Soderberg 2003). Stake (1995, p. 40) claims through qualitative research, we can gain vicarious experiential understanding of subjects understudied. And that, unique experiences of subjects understudied in social science research is where a depth of understanding can be achieved, through analysis of commonality and divergence of the subjects.

The current study adopts the case study design to investigate the phenomenon of women in mining Ghana. According to Yin (2014) the case study method is particularly valid and appropriate when the research targets work organizations, studying subjects in real life situations, and working to answer research questions in the form of 'how,' 'why' and 'what' - similar to the questions in this study seeks to answer. Yin (2014) also justified utilization of case study in works where there is little control over behavioral events for the investigator; when the study focuses on contemporary phenomena (the case) in a real-life / world context, equally in line with the current study on women in mining Ghana. In the perspectives of Yin, the case study design provides rich description of the social scene, deep description of the study context, to further enable a deeper understanding and interpretation of the unique, typical experiences and circumstances of the subjects, and in this case the women miners. Yin (2014) reiterated that the case study method is multi-purpose in nature, global in outlook and used in many situations, both simple and complex to contribute to knowledge and deeper insight into individuals, groups, organizations and society, while still retaining a holistic and real-world perspectives. The examination of data is done within the context of its use or within the situation in which the activity takes place. Also Yin argued that inherent variations, 
influential factors and differential collective approaches to case studies create room for both quantitative and qualitative analysis of data. The real-life nature of the current study, and its strive for deep understanding of mine work organizational gender perspectives, justifies the adoption of the case study approach. It is clear to me that, to understand a complex issue such as this, the case study research is necessary.

The thesis equally opted the multiple-case study approach over the single case. In this regard, as mentioned earlier, four multinational large scale Ghanaian mining companies and a university of mines and technology were understudied. This option draw into Eisenhardt's (1989) argument in favor of multiple cases. Eisenhardt stated that between 4 and 10 cases usually work better. Eisenhardt (1989) emphasizes the use of contrasting observations from multiple cases to create and highlight theoretical constructs. Moreover, by using multiple cases, it's possible to generate testable and generalizable theory. As Eisenhardt, states, multiple case studies "are a powerful means to create theory because they permit replication and extension among individual cases. Eisenhardt (1989) argues that, by using multiple cases, the researcher gets a wider view of the context, making it possible to generate testable and generalizable theory. That to build theory one must have in-depth understanding of the concerned phenomena in a "real-life" setting. The proponents for single-case studies however hold contrary views that, the more cases a researcher investigates, the less contextual insights he or she can communicate (Dyer \& Wilkins 1991; Yin 2014). That less than 3 cases generate knowledge with more complexities and lacking convincing empirical groundings.

\section{Research Context}

This is a context-dependent paper, centered on organizational gender perspectives among multinational Ghanaian mining companies. Ghana is a historic mining country, positioned tenth in the global league of mining nations, and second to South Africa in the Sub-Saharan Africa (AGS, 2015). The understudied companies are situated within Tarkwa-Nsuaem Municipality in the Western Region of Ghana. The municipality forms part of the 22 Metropolitan, Municipal and Districts in the region. Geologically, the area represents part of the south western most extension of well-studied Ashanti Gold Belt that accounts for over 90\% of gold production in Ghana (Akabzaa, Armah \& Baneong-Yakubu 2007) hence justification for choice of the study area.

Figure 1: geological map of the study area 


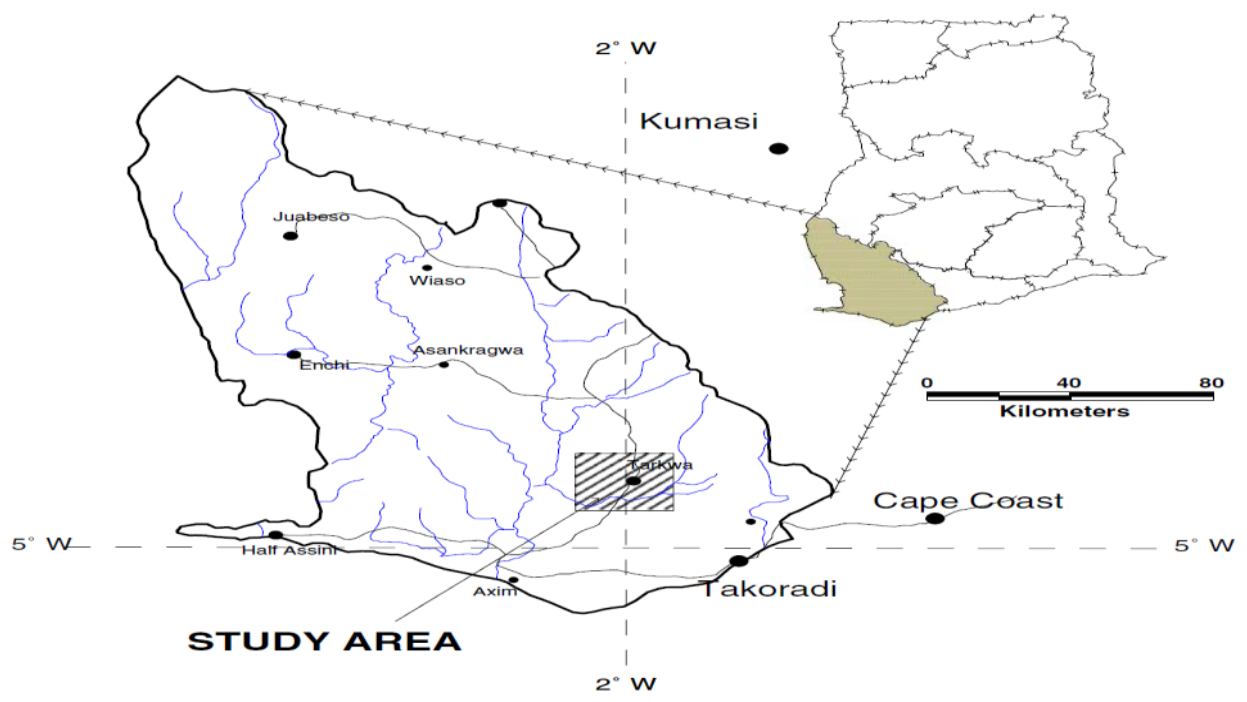

Source: adopted from Akabzaa, Armah and Baneong-Yakubu (2007)

The area hosts the following understudied mining and allied institutions: Gold Fields Ghana Limited Tarkwa branch. A South African owned company, incorporated in 1993 as a legal entity, where the government of Ghana holds a 10 percent free carried interest, as required under the mining law of Ghana. Next is Anglo Gold Ashanti-Iduapriem mines, another South African owned company a $110 \mathrm{~km}$ square concession. Then comes the Golden Star Resources Ltd. in Bogoso, near Tarkwa. A Canadian owned company, incorporated in 1992. The Company holds $90 \%$ interest in both Wassa, Prestea and Bogoso gold mines in Ghana. Then comes the Goldfields Damang Ltd, established in 1997, and mining the tailings of the Abosso Gold Mines. And also University of Mines and Technology (UMaT), a public university established with the aim at producing professionals in the field of mining. It has the mission to promote knowledge through effective teaching, learning, active research and dissemination of information. Of course, choice of these five case units of analysis was also informed by Bent Flyvberg's (2006) information oriented case unit selection strategy, centered at maximizing the utilization of adequate mining information from these units. According to Flyvberg, the information oriented selection, aim at maximizing the utility of information from samples. And that cases are selected on the basis of expectations about their information content, also information is obtained on the significance of various circumstances for case process and outcome.

\section{Procedures, Recordings and Analysis}

i. The field work span between August $24^{\text {th }}$ to December $31^{\text {st }} 2014$, spending a period of 21 days in the field, in two separate field visits.

ii. In all, a total of 27 interviews were conducted, with three focus group discussions. Certainly focus group discussions have the strength of explicit use of group interactions to produce data and insights that would be less accessible if interviewing an individual (Morgan, 1997). 
iii. Both the interviews and focus group discussions were conducted on some lecturers and students from University of Mines and Technology in Tarkwa.

iv. Interviews were conducted on people who held wide range of jobs in the mines; and the mining university, including some mining managers, mining engineers, geologists, mine planners, mineral processors, health, safety and hygiene personnel, environmental, community affairs and public relations officers, mining engineering lecturers and students.

v. Both men and women across the understudied mining companies and the mining university were interviewed at their work places.

vi. The interviews and focus group discussions, averagely lasted between 45-60 minutes each.

vii. A sense of ethical behavior, moral rules and professional codes of conduct were exercised in line with the demands of ethical legislations and requirements. It covered the whole research process, including defining contexts of the study, identifying the research population, sample determination, choice of method to gain access to informants, data collection, analysis, reporting and publication of results. This aimed at protecting interests of the key stakeholders - respondents and their companies or institutions. The conditions being that I sign confidentiality forms and receive training and orientation on basic security, safety and health. I accordingly, in September 2014 took the training, orientation and signed the confidentiality forms. Access to the mining companies was negotiated through their respective Human Resource Managers. Respondents were pre-informed about the impending study, and being mindful of how management sometimes can take employees right to participation for granted, I went further to explain the notion of informed consent to the respondents and further explained that they were free to participate or not, or may start and withdraw when sensing discomfort. Hypothetical names were also designated to respondents on grounds of anonymity (Sieber 1993).

viii. The variables of analysis were a mining and technology university, and 4 multinational Ghanaian mining companies. Both men and women were interviewed; including managers, supervisors, staff, union members and contractors engaged to offer services.

ix. Voice recordings of interviews were done using a tape recorder. Recordings were further transcribed into themes, reflecting the research questions and objectives of the study. And as well, some company documents relevant to the study were sourced and studied.

x. Analysis of data was guided by both literature and aim of the study. All quotes were verbatim and approved by interviewees. Certainly results generated then provide illustrations, typifying the sociocultural barriers affecting women participation, and how dispositions have changed, occasioning shifting gender dynamics, witnessing women taking up Ghanaian mine jobs.

\section{Results}




\section{Sociocultural Barriers Affecting Participation of Women in Ghanaian Mine Jobs}

Regarding the sociocultural barriers, the paper found "common prejudices, perceptions and implicit stereotyped notions on gender roles" as noted participatory barriers to women.

\section{Common prejudice and perceptions}

A section of the Ghanaian society labeled and held the perception that men are able to endure difficult tasks, perform heavy duties and handle machinery better than their women counterparts, as was widely referred to and contained in these responses:

People always say mining is a male job because it involves physical strength. ... 'my own mother sometimes scare me that I will die very early if I continue working in the mines. Instead, I should go for a nursing job.' (Alice, a female geologist 2014)

And

Hmm! These women, when you bring them here, and after sometime, some will go on maternity leave, others start complaining about abdominal pains, irregular menstrual cycles and miscarriages. The end result is that, production suffers. (Amankwa, a male mine manager 2014)

\section{Implicit stereotyped notions on gender roles}

Cultural stereotypes are consistent in associating mine jobs to macho-masculinity. And since mine jobs are highly male skewed, the expectation that males are better miners is strongly and widely upheld in a section of the Ghanaian society. Regrettably, the stereotyped notions that, women lack the ability and strength to perform mine jobs dominated responses in the focus group discussions:

The occupational risk is my major worry! ... and the long term effect of working with vibrations of machines for about ten hours on daily bases is not easy at all. So, we are here for them, and they should be home for us! Society also says 'mining ye bema juma, ' literally means mining is a preserve of the men. ... so in the mines, equal opportunity may be given to everybody, but that everybody, not everybody can come because of the risks associated with the job (Ashraf, a male mine worker 2014).

And:

See! ... when I started work in the mines, people thought I was mad! They said 'mining is very physically challenging, it is tough, it is rough, it is not a natural environment, especially underground mining!' (Adjele, a female mine worker 2014).

\section{Shifting Gender Dynamics in Multinational Ghanaian Mine Jobs}

Beyond the sociocultural barriers, the paper showcased change processes in background dispositions, witnessing a shift in gender dynamics with more women taking up mine jobs within the multinational Ghanaian mining industry. The observed change processes include - "the dawn of women in mining" "towards a gender-driven mining initiatives" and "the ore-solidarity movement.", 


\section{The dawn of women miners}

Established in 1952 as Tarkwa Technical Institute, affiliated with Kwame Nkrumah University of Science and Technology as Tarkwa School of Mines in 1976, subsequently assumed a full fledge university status in 2007, now known and called University of Mines and Technology (UMaT). However, since inception, the university only admitted first female in 2000, and by 2014 over 20 $\%$ of the total student population were women and management of the university had this to say:

[...] we have been making deliberate effort to encourage women to come, by giving them some leverage, for that reason we instituted what is called gender mainstreaming. This means the moment a woman gets aggregate 36, that is maximum aggregate or minimum point of entry qualification, and we see that she chooses mining related programme, we will give it to her! Whereas their male counterparts with aggregate 10 or 14 may not probably be considered (Management of UMaT, 2014)

The core competence and capabilities of women pursuing mining and mining related courses in the university was never questioned at all by the authorities, as captured in these responses:

[...] the women we admitted over the years have proven us right, and performed very well! For the past two years running (2011/2012 and 2012/2013 academic years) female students have been picking the overall best student awards in this university (Management of UMaT, 2014).

And that:

[...] women engineers in this university are doing very well in industry, we have been receiving positive feedbacks on them, from their employers and in most cases they are being treated as expatriates (Management of UMaT, 2014)

\section{Towards a gender-driven mining}

The knowledge of the fact that making any business sustainable and relevant, you cannot cut out women, hence the Ghanaian mining companies adopt critical gender driven mining steps such as policies either on gender equality or women's empowerment or diversity or sustainable management as captured in Anglo Gold Ashanti's gender equality and women's empowerment policy document which is a reflection of the other companies:

The main purpose of this policy is to serve as a tool and framework for enhancing gender equality in the workplace and to enable the company to integrate gender into key organizational practices. Further, it suggests the development of specific interventions to meet the practical and strategic needs of women in order to ensure the empowerment of women as a step towards gender equality (2015:1).

Also:

I have been here for 9 to 10 years, and from my personal experience, we gave females the opportunity to work in various areas, including being trained to use dump trucks. For example, we recruited and trained about 15 women around 2008/2009. And this among 
other reasons, was to encourage the women living around this community to take up mining professions to rub shoulders with the men (Ishmael, a male mine manager 2014).

And that:

[...] there has been shifts from underground to open pit method of mining, which is an excavation at the surface of the ground for the purpose of extracting ore. The open pit mining does offer some advantages: more cost effective, safer working conditions, no risk of cave in or toxic gas, and more and more women attracted as a result, leading to improve our women recruitment and retention drive (Frema, a female mine PR manager 2014).

\section{The ore solidarity}

The ore solidarity epitomizes Women in Mining Ghana (WIM), an organization founded and composed of all Ghanaian women employed and working in the mining industry. In a focus group discussion, individual members had this to say, which reflected the entire groups' expectations, aspirations and orientations:

Our numbers are low, this is historical, not beginning today, so we are playing a catch up! It is not about a man is better than a woman or a woman is better than a man! It is about making money, if the guys are working there, why we can 't apply to get jobs there!

[...] by so doing, we want to encourage more women to work in mining, we also work to encourage those women who are already working in the mines. We are a deep voice for them, we helping each other because it is tough as well, especially those who work at site, due to our natural and first jobs as being mothers, sometimes it is a bit difficult for women to work in the sector as well, and so we need solutions.

[...] of course the commodity prices are really bad...the word out there is sustainability, and to make any business sustainable and relevant, you cannot cut out women! You know, in Africa women make up $70 \%$ of the total population and in Ghana, 51\% are women. Why? Why don't you want to employ the women!

And that:

I don't want to believe in limitations, neither do I believe in a man's world or a woman's world, I believe in people's world!

\section{Discussions}

\section{Sociocultural Barriers Affecting Participation of Women in Ghanaian Mine Jobs}

The discussion opens and done, first within the context of sociocultural barriers affecting effective mine work participation of women. The paper found 'common prejudices, perceptions and implicit stereotyped notions on gender roles.' This outcome supports Yakovleva (2007) in her earlier work that measured women's participation in Ghanaian mining industry. She identified sociocultural barriers and family commitments imposing heavy burdens on women, hindering their independence and effectiveness to participate in mine works. This further resonate in the structuralists' theory bothering on binary oppositions and hierarchical privileges. A perceived unjustifiable privileges that juxtaposes how the former dominate and occupy a command over the 
later (Levi-Straus, 1973). And a classic demonstration of 'doing gender' and how societal and organizational gendered natures have been socially constructed and sustained as posited by West and Zimmerman (1987).

The paper further shows how sociocultural barriers grow to influence and cause organizational barriers. Regard the expression that "my mother says I should have opted a nursing profession...that I will die early if I continue working in the mines.' This is a typical demonstration of how global problems become local; and how societal problems diffuse into organizations. In this paper, this occurrence is termed 'socio-osmosis' - defining a gradient diffusion and movement of sociocultural beliefs into the basic fabric of the mine work organizations. These set of sociocultural barriers in the form of implicit stereotyped notions, though they may appear unfounded but could carry negative effects on women's mine work participation. In line with the doing gender theory of West and Zimmerman (1989). These designated preconceived gender roles and uninformed professional identity judgements, are characterized by preclusionary or exclusionary effect of preventing individuals, in this case, women, from pursuing their life time career interest further.

Admittedly, the sociocultural barriers also fall under the category of informal barriers, which are sometimes very difficult to break, though many of the formal barriers may have been broken (Andersson et al2013). Andersson et al however reiterated - "with perseverance, everything is possible!' In response to this 'perseverance call' this paper observes stakeholders in Ghanaian mines repositioning themselves, making continuous commitment, with adherence to beliefs and course of actions leading to gender equality awareness in the mines. And certainly, results from the current study shows the image of the mining industry of Ghana is changing, the goal poles are shifting, witnessing gradual lifting of some of the barriers, with bridges being built, and more women are now taking up mine jobs. Synonymous to West and Zimmerman (1987) who foreground potential changeability claim on sociocultural attitudes between women and men with wide variations within and among cultures.

\section{Shifting Gender Dynamics in Multinational Ghanaian Mine Jobs}

This part of the discussion centres on the change regimes among the multinational Ghanaian mines, taking into account - " the dawn of women miners" " towards a gender-driven mining" and "the ore-solidarity movement." Regarding the dawn of women miners, evidence abound in academia, where a Mining and Technology University in Ghana, has introduced set of initiatives, practices and policies in the form of quota systems, and gender mainstreaming in their admission programs, aim at augmenting women enrolments into the university, after it has been 'doing gender' over four decades in its admission regimes. This affirmative stance of the university corroborates the Science, Technology and Mathematics Education clinics, instituted in Ghana in 1987, aim at promoting and popularizing science and technology education among girls. The gender equality policy interventions, as instituted by the university, equally resonate with 'undoing gender theory' of Butler (2004), Lorber's (2000) notion of 'degendering', and Risman's (1998) conception of "gender vertigo" all of which argued in support of dismantling gender by putting in place policies, systems, structures and programs aim at deconstruction of gender in the world of work.

The paper also show-cased ' the towards gender-driven mining initiatives' witnessing the mining companies put in place set of policies on gender equality and women's empowerment, diversity or 
sustainability management. Their recruitment efforts targeting women, women network groups springing within the mines, and skills development programs being organized for women. This result supports (Butler 2004; Deutsch 2007) and the undoing gender theory, which proposed a paradigm shift from "doing gender" to illuminating social interactions and organizational policies, processes and practices that reduce gender differences, and avoiding the usage of stereotypes in evaluating women. Though the mining companies are making frantic effort towards achieving gender equality in both admission and recruitment programs, the impact remains qualitative, as quantitatively women representation is still low. The implication of this being a 'continuous culture of preserving gender patterns, what Abrahamsson (2014) suspects could lead to a less productive work, as well as a problematic work environment.

Then comes the golden age of 'ore solidarity movement' witnessing the formation of Women in Mining-Ghana. An organization composed of women employed in the Ghanaian mining industry. Of course, being in a male-dominated setting, against the knowledge of the fact that 'in numbers lie strength' these women felt their purposes, values and orientations could best be served via self and resources mobilization. Hence, the formation of the 'ore solidarity' a vanguard, which works to instituting and promoting "barrier breaking" and "boundary crossing' moves such as educational, scientific, legislative, career development and other programs as will foster gender awareness as well as ensuring gender equality in the mine works. Certainly, this ore solidarity movement bears both functional and structural similitude with the new social movement theory as discussed earlier in (Touraine, 2002; Melucci, 1995; Braig \& Wölte, 2002; Barry et al, 2012). First and foremost, the women in mining Ghana were observed acting collectively as well as separately, sharing common values and orientations that are oppositional to the status quo of women in the mine jobs of Ghana. This function affirms the prime feature of the new social movement theory. Secondly, the ore solidarity movement emerged in a grand style, spontaneously judged the time was due to step forward, in expressed dissatisfaction with the long standing masculine dominant cultures in the mines, with its associated gender inequalities, hence a desire for change - in terms of recruitment policies and practices that are gender balanced in the world of Ghanaian mine jobs. And thirdly, the ore solidarity was formed, with its core values and orientations permeating the social fabric of mining and allied mining institutions through complex web of interactions.

The women in mining Ghana equally explore available platforms, with deep voices, deploying networks of civil society, political think tanks and the offices of Ghana Chamber of Mines to advocate, lobby and exchange ideas towards a gender neutral mining. Even in Europe, where the new social movement approach originated, studies have confirmed their processes of networks and collective orientations (Melluci 1995). Other studies also examined women movements as worldwide phenomena (Braig and Wolte, 2002; Acker, 1992) drew attention to their historical significance in helping to facilitate the advancement of women in men-dominant settings in the mist of the masculine cultural dominance.

\section{Implications and Conclusion}

Results from the current paper suggest an existence of sociocultural barriers, notably common prejudice, perceptions and implicit stereotyped notions on gender roles in the mines. This development has practical implications for practice: first it infuses uninformed professional 
identity judgements, characterized with exclusionary effect of preventing women from flexible pursuance of their life time career interests, hence hindrance to their self-actualization drives especially in mine jobs. This will equally imply a continuous perpetuation and conservation of dominant masculine cultures in mine works of Ghana. A phenomena that questions the mining companies' modern organizational status. Also, the prejudices and stereotypes equally implies increased casualization of women workers in the mines, with consequential effect of feminizing poverty, since the mines are among the top high paying jobs in Ghana. Therefore, goals on gender equality, and women's empowerment attainment becomes very difficult in the world of mining.

Contrarily, the gender equality effort among the mine work organizations implies their huge subscription to modern organizational models, with high propensity of effecting organizational change, and possibilities of creating effective and good work environment for both men and women. This will also promote diversity and inclusivity in the mine works of Ghana, a prerequisite for high mine work productivity. And of course, gender equality in the mines may also well connect to a good corporate governance and a gender-driven social innovative mining.

In conclusion, results from the current study suggests an existence of sociocultural barriers, notably common prejudice, perceptions and stereotype in the mines. This proffer an answer to the first research question: what are the sociocultural barriers affecting participation of women in multinational Ghanaian mines? Also, the paper identifies a regime of change in background dispositions, witnessing gender mainstreaming in admission programs, and mining operations, the dawn of women miners, towards a gender driven mining initiatives and the ore solidarity agenda, suggesting a shift in gender dynamics of the mine work profession in Ghana. This resonates well with the 'undoing gender' and 'the new social movement's theories' juxtaposing the processes of change in the world of mine work, especially with changes emerging from organizational gender perspectives, witnessing women in active, politicized and solidarized moves as weapons of the weak and little winds. Working alongside the mining companies and allied institutions, deploying modern organizational models, aim at dismantling self-seeking interest in pursuance of collective values and orientations in the form of a progressive but slow moves toward achieving gender equality in the mines. This equally provides an answer to the second research question: beyond the barriers, what changes have occurred, witnessing more women taking up mine jobs within the multinational Ghanaian mines? The current study by design is limited to large-scale Ghanaian mines, against the knowledge of the fact that, artisanal and small scale mining also do exist. And while the former is formalized in terms of hierarchal authority structures with well-functioning human resource outfits, the latter is characterized with informalities. And certainly, it would be of future research interest to design a comparative study to establish the contrast on mine works gender perspectives between large-scale formal and small-scale informal mines.

\section{References}

Abrahamsson, L. (2006). Exploring construction of gendered identities at work, pp. 105-121. In Billet, S., Fenwick, T. and Somerville, M. (eds) Work, Subjectivity and Learning. Understanding Learning through Working Life. Dordrecht: Springer.

Abrahamsson, J. (2014). Gender and the modern organization, ten years after. Nordic journal of 
working life studies 4, 4, $109-136$.

Acker, J. (1992) Gendering organizational theory. In gendering organizational Analysis (ed.)

Albert J. Mills and Peta Tancred, 248-60. Newbury Park CA: Sage.

Ahmad, N. \& Lahiri-Dutt, K. (2006). Engendering Mining Communities Examining the Missing Concerns in Coal Mining Displacement and Rehabilitation in India. Gender, Technology and Development, 10 (3), 313-339.

Akabzaa, T. M., Armah T.E.K and Baneong-Yakubo (2007). Prediction of acid mine drainage generation potential in selected mines in the Ashanti Metallogenic Belt using static geochemical methods. Environ Geol 52, 957-964.

Alexander, P. (2007). Women and Coal Mining in India and South Africa. African Studies 66, 2, 201-222.

American Geological Survey 2010/2015.

Ampofo, A. A. (Ed) (2014). Gender and Society in Africa-An Introduction. Accra: Sub Saharan Publishers.

Amutabi, M. and Lutta-Mukheiba, M. (2001). Gender and mining in Kenya: the case of Mukibiri mines in Vihiga District. A journal of culture and African women studies 1, 2, $133-141$.

Andersson, A., Faltholm, Y., Abrahamsson, L. and Lindberg, M. (2013). Breaking ore and gender patterns. A gender - aware and socially sustainable research and innovation agenda for Swedish mining industry. Lulea Technology University

Apusiga, A, (1987). A Dimension of Sex Discrimination: The Ghanaian Working Woman's Experience. Journal of Administration Vol. 7, Nos. 3 and 4.

Barry, J., Chandler, J. and Berg, E. (2007). Women's movements and new public management: higher education in Sweden and England. Public Administration, 85, 1, 103-22.

Barry, J., Berg, E. and Chandler, J (2012) Movement and Coalition in Contention: Gender, Management and Academe in England and Sweden. Gender, Work \& Organizations, 19, $1,52-70$.

Benya, A. (2009) Women in mining: A challenge to occupational culture in mines. Masters

Dissertation. University of the Witwatersrand, Johannesburg.

Butler, J. (2004) Undoing Gender. New York/London: Rpoutledge.

Connell, R. (1985) Theorising gender. Sociology 19, 260-72.

Czarniawska, B. and Hoepfl, H. (2002) (eds) Casting the Other. London: Routledge.

Deutsch, F. M. (2007) Undoing gender. Gender and Society, 21, 1, 106-127. 
Dyer, W.G. and Wilkins, A.L. (1991) Better stories, not better constructs, to generate better theory: A rejoinder to Eisenhardt. Academy of Management Review, 16, 3, 613-61.

Eisenhardt, K.M. (1989) Building Theories from Case Study Research. Academy of Management Review, 14, 4, 532-550.

Flyvbjerg, B. (2006) Five misunderstandings about case-study research. Qualitative Inquiry 12 (2), 219-245.

Gioia, D. and Chittipeddi, K. (1991) In Holgersson, C. (2013). Recruiting Managing Directors: Doing Homosociality. Gender, Work \& Organization, 20,4, 454 - 466.

Harvey, J. (2005). A Brief History of Neoliberalism. Oxford: University Press.

Hearn, J. (1992). Men in the public eye: The construction and deconstruction of public men and public patriarchies. London: Routledge.

Kilu, R.H., Sanda, M-A. Eira, A. and Uden M. (in press) Reflections on Organizational Barriers Vis-à-Vis Women Participation in Large scale Ghanaian Mines.

Lahiri-Dutt K. and Martha Macintyre (2006). Women miners in developing countries: Pit women and others. USA: Ashgate publishing Ltd.

Lahiri-Dutt K. (2011) The Megaproject of mining: a feminist critique. In Brunn, S.D. (ed.), Engineering Earth, Springer.

Lévi-Strauss, C. (1976) Structural Anthropology Volume II. New York: Basic Books Inc.

Linstead, S. and Pullen, A. (2006) Gender as multiplicity: desire, displacement, difference and dispersion. Human Relations, 59,9, 1287-310.

Lorber, J. (2000). Using gender to undo gender: a feminist degendering movement. Feminist Theory $1,79$.

Melucci, A. (1995). The process of collective identity. In Johnston, H. and Klandermans, B. (eds) (1995) Social Movements and Culture p. 41-63. London: UCL Press.

Melucci, A. (1997). Identity and Difference in a Globalized World. London: Zed Books.

Morgan, D. L. (1997). Focus Groups as Qualitative Research. London: Sage Publications.

Olofsson, J. (2010) Taking place - augmenting space. Spatial diffusion in times of technological change. Doctoral thesis. Lulea University of Technology.

Poggio, B. (2006) Editorial: outline of a theory of gender practices. Gender, Work \& Organization, 13 (3), 225-33. 
Risman, B. J. (1998). Gender vertigo. New Haven CT: Yale University Press.

Sieber, J. (1993). Ethics of social research: fieldwork, regulation and publication. New York: Pringer-Verlag.

Stake, R.E. (1995). The Art of Case Study Research. London: Sage Publications.

Touraine, A. (2002) The importance of social movements. Social Movement Studies 1,1, 89-95.

West, C. and Zimmerman, D. H. (1987). Doing gender. Gender and Society 1,2, 125-151.

Yakovleva, N. (2007) Perspectives on Female Participation in Artisanal and Small Scale Mining: A Case Study of Birim North District of Ghana. Resources Policy 32,3, 29-41.

Yin, R.K. (2014). Case study research: Design and methods (5th edition). London: Sage.

Wajcman, J. (2010) Feminist theories of technology. Cambridge Journal of Economics 34,4, 143152. 